\title{
Porsche 919 Hybrid - Background of development
}

Malte Huneke, Dr. Ing. h.c. F. Porsche AG

This manuscript is not available according to publishing restriction.

Thank you for your understanding.

(C) Springer Fachmedien Wiesbaden GmbH 2017

M. Bargende, H.-C. Reuss, J. Wiedemann (Hrsg.), 17. Internationales Stuttgarter Symposium, Proceedings, DOI 10.1007/978-3-658-16988-6_5 